\title{
A New Format for Dermatologica
}

\section{J.-H. \\ Saurat}

\section{Genève}

Since January 1989 Dermatologica is being published in a new size of 210x280 mm, this larger format has been finally chosen instead of the almost centenary small 177x252 mm format for numerous reasons. I heard from several readers that they were disappointed that 'also Dermatologica' was sacrificing 'to current fashion'. In fact, this new size is much better adapted to today's requirements of a journal; it therefore represents one of the several actions taken in the frame of the operation 'new look for an old journal' , as stated in a previous editorial in 1986. By doing so, for reasons of cost, we had to include only 4 instead of 6 issues per volume, which represents exactly the same number of published papers. We hope that with the help of the publisher we will be able to rapidly return to

12 issues a year, which would represent an increase of $70 \%$ of printed pages compared to the 12 issues in the smaller format. This would allow us to accommodate more papers and decrease the number of works submitted that could not be accepted for lack of space. The aim of this editorial board is to provide dermatologists with a widely distributed journal that will allow them to express their views through an electic peer review process since the reviewers are chosen in all parts of the world. It is hoped that one of the 'old ladies' of continental Europe dermatological journals will pursue her quest for youth and succeed even better than if she used 'topical retinoic acid three times a day'.

J.-H. Saurat 